\title{
Different reactions obtained using the same DNA detection reagents for Thai and Korean hepatopancreatic parvovirus of penaeid shrimp
}

\author{
Jurairat Phromjai ${ }^{1}$, Wasana Sukhumsirichart ${ }^{2}$, C. Pantoja ${ }^{3}$, D. V. Lightner ${ }^{3}$, T. W. Flegel ${ }^{1, *}$ \\ ${ }^{1}$ Department of Biotechnology, Faculty of Science, Mahidol University, Bangkok 10400, Thailand \\ ${ }^{2}$ Department Biochemistry, Faculty of Medicine, Srinakharinwirote University, Sukhumvit 23, Bangkok 10110, Thailand \\ ${ }^{3}$ Department of Veterinary Science and Microbiology, University of Arizona, 1117 E. Lowell St., Bldg. \#90, Room 114, Tucson, \\ Arizona 85721, USA
}

\begin{abstract}
Hepatopancreatic parvovirus (HPV) can cause stunted growth and death in penaeid shrimp including Penaeus monodon. We used PCR primers and a commercial DNA probe designed from HPV of Penaeus chinensis (HPVchin) to examine HPV-infected Thai P. monodon (HPVmon). We found that the PCR primers produced a $732 \mathrm{bp}$ DNA amplicon rather than the $350 \mathrm{bp}$ amplicon obtained with HPVchin template and that the DNA probe gave weak to variable in situ DNA hybridization results. In addition, hybridization to PCR products from HPVmon was weak compared with hybridization with PCR products from HPVchin. By contrast, the $732 \mathrm{bp}$ amplicon hybridized strongly with HPVmon-infected cells by in situ hybridization but not with uninfected shrimp tissue or other shrimp viruses, thus confirming its origin from HPVmon. Cloning, sequencing and analysis of the $732 \mathrm{bp}$ amplicon showed that $696 \mathrm{bp}$ (excluding the primer sequences) contained $47 \%$ GC content and had only $78 \%$ homology to 701 aligned bases from a $3350 \mathrm{bp}$ DNA fragment of HPVchin from GenBank. These results explain why the reagents based on HPVchin gave a different PCR product and weak hybridization results with HPVmon, and they show that multiple primers or degenerate primers may be necessary for general detection of HPV varieties. Together with previously published information on the estimated total genome sizes for HPVchin (approximately $4 \mathrm{~kb}$ ) and HPVmon (approximately $6 \mathrm{~kb}$ ), these data support the contention that HPVchin and HPVmon are different varieties or species, in spite of their similar histopathology.
\end{abstract}

KEY WORDS: Hepatopancreatic parvovirus - Penaeus monodon $\cdot$ Penaeus chinensis $\cdot$ Polymerase chain reaction

$$
\text { Resale or republication not permitted }
$$
without written consent of the publisher

Hepatopancreatic parvovirus (HPV) has been reported in the postlarvae and juveniles of penaeid shrimp and can cause slow growth and death (Lightner 1996, Flegel et al. 1999). However, the virus has not yet been successfully transmitted in the laboratory and information about natural modes of transmission and

${ }^{*}$ Corresponding author. E-mail: sctwf@mahidol.ac.th possible reservoir species remain unanswered (Flegel 1997, Flegel et al. 1999).

HPV was first reported in postlarvae of Penaeus chinensis, also called Fenneropenaeus chinensis (Lightner \& Redman 1985). It was later reported from Thailand (Flegel et al. 1992), where it was subsequently found to be statistically correlated with stunted growth and thus could result in significant economic loss to Thai shrimp farmers (Flegel et al. 1999).

Diagnosis of HPV historically depended on the histological evidence by hematoxylin and eosin staining of characteristic basophilic inclusions in enlarged nuclei of tubule epithelial cells of the hepatopancreas. As with other parvoviruses, it occurs predominantly in the rapidly dividing E-cells at the distal end of the hepatopancreas tubules. Early HPV inclusions initially appear as small eosinophilic areas adjacent to the nucleolus. These enlarge to form giant, basophilic inclusions in hypertrophied nuclei often accompanied by an adjacent nucleolus that is compressed and crescent shaped (Lightner 1996). For normal histological analysis, sampled shrimp must be fixed, embedded and sectioned. At least $2 \mathrm{~d}$ are usually required before this destructive process and slide analysis are completed. Although rapid smears of the hepatopancreas can be prepared (Lightner et al. 1993) and thus eliminate the need for embedding and sectioning, the sampled shrimp must be killed and some experience is needed to recognize HPV inclusions in the smears.

Although the designation HPV is based on the common histopathological appearance of infected tissues, it is possible that different strains, varieties or species of the causative agent might exist. Indeed, a commercial DNA probe developed from HPV of Penaeus chinensis did not give positive hybridization results with HPV from Macrobrachium rosenbergii from Malaysia 
(Lightner et al. 1994). To determine differences more precisely, molecular methods and ultimately DNA sequence comparisons are necessary, as has been done with Baculovirus penaei (Durand et al. 1998) and for white spot syndrome virus (Lo et al. 1999).

HPV has been isolated and characterized from Penaeus chinensis (HPVchin) from Korea (Bonami et al. 1995) and from P. monodon (HPVmon) from Thailand (Sukhumsirichart et al. 1999). Both viruses comprise unenveloped, icosahedral particles of approximately 22 to $24 \mathrm{~nm}$ diameter, as seen by negative staining for TEM. The nucleic acid of both is singlestranded DNA, although the genome size of HPVchin was reported to be 4 to $4.3 \mathrm{~kb}$ while that of HPVmon was reported to be $5.8 \mathrm{~kb}$. Based on genome size, it appeared that HPVchin and HPVmon were quite different. However, further study of their nucleotide sequences and putative amino acid sequences was required to confirm this.

The availablility of a diagnostic DNA probe and PCR primers for HPVchin from DiagXotics Co. Ltd (Wilton, $\mathrm{CT}$, USA) has allowed for the non-destructive detection of HPV by PCR amplification and dot blot hybridization using shrimp fecal samples (Mari et al. 1995). The probe did react by in situ hybridization with HPVmon (D. V. Lightner \& T. W. Flegel unpubl. data) indicating some genetic relationship, even though it did not react with HPV from Macrobrachium rosenbergii from Malaysia (Lightner et al. 1994). Recent publications by Sukhumsirichart et al. (1999) and Pantoja \& Lightner (2000) have also presented PCR assays for HPV. These use different sets of primers from those marketed by DiagXotics. Based on in situ hybridization results with the DiagXotics probe, it was expected that PCR primers designed for HPVchin would also be useful for detection of HPVmon. However, our results showed that they were not particularly efficient.

Materials and methods. Viral preparations: HPV from juvenile Peneaus monodon was isolated from naturally infected shrimp randomly sampled from a commercial shrimp pond in Songkhla Province, southern Thailand in 1995. Infections were verified by normal histological methods (Lightner 1996). The virus was subsequently purified from pooled hepatopancreata and DNA was extracted as described by Sukumsirichart et al. (1999).

PCR amplification: PCR primers, positive control template and a digoxygenin-labeled probe developed from Korean HPV (HPVchin) were obtained from DiagXotics Co. Ltd. This primer set (K350) comprised 7852 primer-Lot \# 068452 and 7490 primer-Lot \# 06845, each with 18 nucleotides and respective melting temperatures of 56 and $58^{\circ} \mathrm{C}$. According to the manufacturer, these primers would give a $350 \mathrm{bp}$ amplicon from an HPV DNA template.
PCR amplifications were performed in a final volume of $50 \mu l$. The mixture contained $1 \times$ PCR buffer II (50 $\mathrm{mM} \mathrm{KCl}$ and $10 \mathrm{mM}$ Tris- $-\mathrm{HCl}, \mathrm{pH} 8.3), 1.5 \mathrm{mM}$ $\mathrm{MgCl}_{2}, 200 \mu \mathrm{mol}$ of each deoxyribonucleoside-5'triphosphate (dNTP), $0.4 \mu \mathrm{mol}$ of each primer, 1.25 units AmpliTaq DNA polymerase and varied concentrations of DNA template. The reaction volume was adjusted with sterile double-distilled water to $50 \mu \mathrm{l}$. The mixture was subjected to amplification in a PCR Thermal Cycler (Gene Amp PCR system 2400, Perkin Elmer, Foster City, CA, USA) for 35 cycles. For PCR, the initial denaturation (prePCR) was at $94^{\circ} \mathrm{C}$ for $5 \mathrm{~min}$, followed by 35 cycles of denaturing at $94^{\circ} \mathrm{C}$ for $1 \mathrm{~min}$, annealing at $55^{\circ} \mathrm{C}$ for $1 \mathrm{~min}$ and extension at $72^{\circ} \mathrm{C}$ for $1 \mathrm{~min}$, followed by final extension (postPCR) at $72^{\circ} \mathrm{C}$ for 7 min. An HPV control template from DiagXotics Inc. was used as a positive control while sterile doubledistilled water was the negative-control template. For sensitivity tests, the DiagXotics control template and purified HPVmon DNA were serially diluted with double-distilled water. PCR products were analyzed by standard agarose gel electrophoresis with $\varnothing \times 174$ / HaeIII DNA as the molecular marker (Sambrook et al. 1989), visualized by UV light on a transilluminator and photographed using Polaroid film.

Digoxygenin labeling: The HPVmon 732 bp amplicon was labeled with digoxigenin-11-dUTP (DIGdUTP) by the random prime method using the PCR amplification protocol described above but with the replacement of the dNTP regents by a dNTP mixture containing DIG-dUTP (PCR DIG Labelling Mix from Boehringer Mannheim, Mannheim, Germany; Cat. No. $1585550)$ in the PCR reaction mixture. The labeled PCR product was then purified using a High Pure PCR product purification kit (Boehringer Mannheim, Cat. No. 1732668 ).

Southern blot hybridization: After agarose electrophoresis, DNA patterns were transferred to nylon membranes using sandwich blotting following the protocol of Sambrook et al. (1989). The HPV DiagXotics probe was labeled with DIG-dUTP. The concentration of probe for hybridization was $10 \mathrm{ng} \mathrm{m}^{-1}$. Hybridization was carried out for $8 \mathrm{~h}$ at $68^{\circ} \mathrm{C}$ and membranes were washed twice for $5 \mathrm{~min}$ each at room temperature and then twice for $15 \mathrm{~min}$ each at $68^{\circ} \mathrm{C}$. Colorimetric detection after Southern transfer were performed using a DIG nucleic acid detection kit based on antidigoxygenin alkaline phosphatase conjugate according to the manufacturer's directions (Boehringer Mannheim, Cat. No. 1175041). A positive reaction gave an insoluble blue-black precipitate with nitroblue tetrazolium salt substrate.

Cloning and sequencing of DNA: DNA fragments purified from agarose gels were ligated to the ECoRI and SpeI site of pGEM $^{\circledR}$-T easy vector (Promega Corp., 
Madison, WI, USA) following the Promega manual protocol. The ligated product was transformed into Escherichia coli DH5 $\alpha$. Transformed cells were spread together with $50 \mu \mathrm{l}$ of $20 \mathrm{mg} \mathrm{ml}^{-1} \mathrm{X}$-gal in dimethylformamide solution on Luria Bertani (LB) agar (LB broth, Difco, Detroit, MI, USA, plus $1.5 \%$ agar) containing $50 \mu \mathrm{g} \mathrm{ml}^{-1}$ of ampicillin. Approximately 30 white colonies were selected as positive transformants and confirmed by colony blot hybridization with the digoxygenin labeled 732 bp product from HPVmon. Plasmids were then purified, digested with EcoRI and SpeI, and checked by agarose gel electrophoresis. All 30 isolates showed inserts of approximately $732 \mathrm{bp}$. Three clones were sequenced from both DNA strands using an ABI PRISM Dye Terminator Cycle Ready Reaction Kit (Perkin Elmer) with an ABI PRISM 377 automated DNA sequencer.

Sequence comparisons: Sequence information from HPVmon was compared with that given for HPVchin in the GenBank database (Accession number AY008257, Pantoja \& Lightner, direct submission). Comparisons were made using Clustal computer software (version 7) and Clustal W at the European Bioinformatics Institute website (www2.ebi.ac.uk/clustalw/).

In situ hybridization: Penaeus monodon specimens preserved in Davidson's fixative (95\% ethanol $330 \mathrm{ml}$, formaldehyde $220 \mathrm{ml}$, glacial acetic acid $115 \mathrm{ml}$ and tap water $335 \mathrm{ml}$ ) were histologically prepared as paraffin-embedded tissues (Bell \& Lightner 1988). The embedded samples were cut to 5 to $6 \mu \mathrm{m}$ thickness and processed on Fisher ProbeOn Plus microscope slides (Fisher Scientific, Pittsburgh, PA, USA) for in situ hybridization using non-radioactive DIG-11-dUTP labeled probe according to the instructions in the Boehringer Mannheim Genius kit manual.

Results and discussion. PCR amplification and Southern blot hybridization: When the commercial DiagXotics primers were used for PCR with DNA template from HPVchin and HPVmon (100 pg each of DiagXotics control DNA and HPVmon DNA), the HPVchin control template gave a single amplicon of approximately $350 \mathrm{bp}$, and HPVmon gave 2 amplicons, 1 intense product at $732 \mathrm{bp}$ and a very weak product at $350 \mathrm{bp}$ (Fig. 1). These sample results are consistent with the examination of more than 50 field samples of Penaeus monodon collected from shrimp farms in Thailand. A sensitivity test (Fig. 2) with the DiagXotics primers showed that as little as $0.01 \mathrm{pg}$ or $10 \mathrm{fg}$ of HPVchin control template gave a strong product for the expected amplicon at approximately $350 \mathrm{bp}$ in agarose electrophoresis gels (Fig. 2, lane 4). By contrast, the lowest concentration of Thai HPVmon DNA that gave a clearly visible product was $1 \mathrm{pg}$, (at least 100 times higher concentration) (Fig. 2, lane 2). In addition, there was only 1 detectable product at $732 \mathrm{bp}$

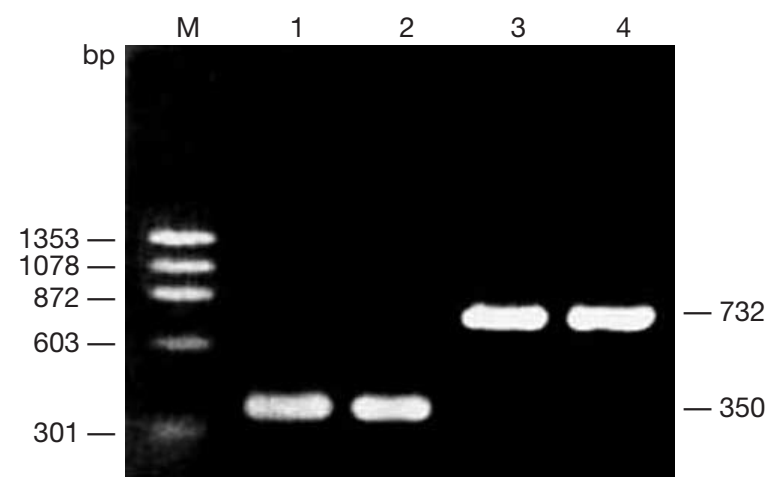

Fig. 1. Agarose gel electrophoresis of PCR amplicons from hepatopancreatic parvovirus (HPV) DNA using DiagXotics primers. Lanes 1 and 2: DiagXotics HPV (HPVchin) control template giving a $350 \mathrm{bp}$ amplicon only. Lanes 3 and 4: Thai HPVmon template giving 2 amplicons, an intense band at $732 \mathrm{bp}$ and a very weak band at $350 \mathrm{bp}$, not visible in the photograph. Lane M: $\varnothing \times 174 /$ HaeIII DNA size marker

for this concentration of template (see Fig. 4). These results indicated that the commercial primers and PCR conditions for HPVchin were not ideal for HPVmon, possibly because of differences in nucleic acid sequence at the primer sites.

In situ hybridization: All histological samples used were first screened by hematoxylin and eosin staining for histopathology characteristic of HPV infection. When the DiagXotics probe OF44 was used for in situ hybridization with paraffin-embedded sections of Penaeus monodon infected with HPVmon, weak and variable signals or no signals were found in the characteristic hypertrophied nuclei of infected hepatopancreatic tubule cells (Fig. 3A). This contrasted with results reported for OF44 when used with HPVchin

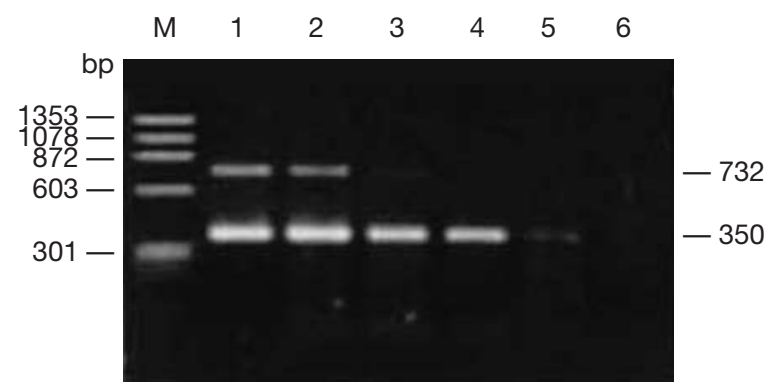

Fig. 2. Agarose gel showing comparative sensitivity of DiagXotics primers with HPVchin and HPVmon templates. The PCR reactions were run separately with parallel 10 -fold serial dilutions of purified HPV DNA template ranging from 100 to $0.01 \mathrm{pg}$. After the PCR reactions, vials with the same template concentration were mixed to run the gel so that relative sensitivities could be more easily visualized. Lane $M$ : $\varnothing \times 174 /$ HaeIII DNA size marker. Lanes 1 to 5: upper bands show the 732 bp HPVmon DNA amplicons with the last visible band in lane $3(0.1 \mathrm{pg})$, while the lower bands show $350 \mathrm{bp}$ HPVchin amplicons with the last visible band in lane 5 (0.01 pg). Lane 6: negative control 

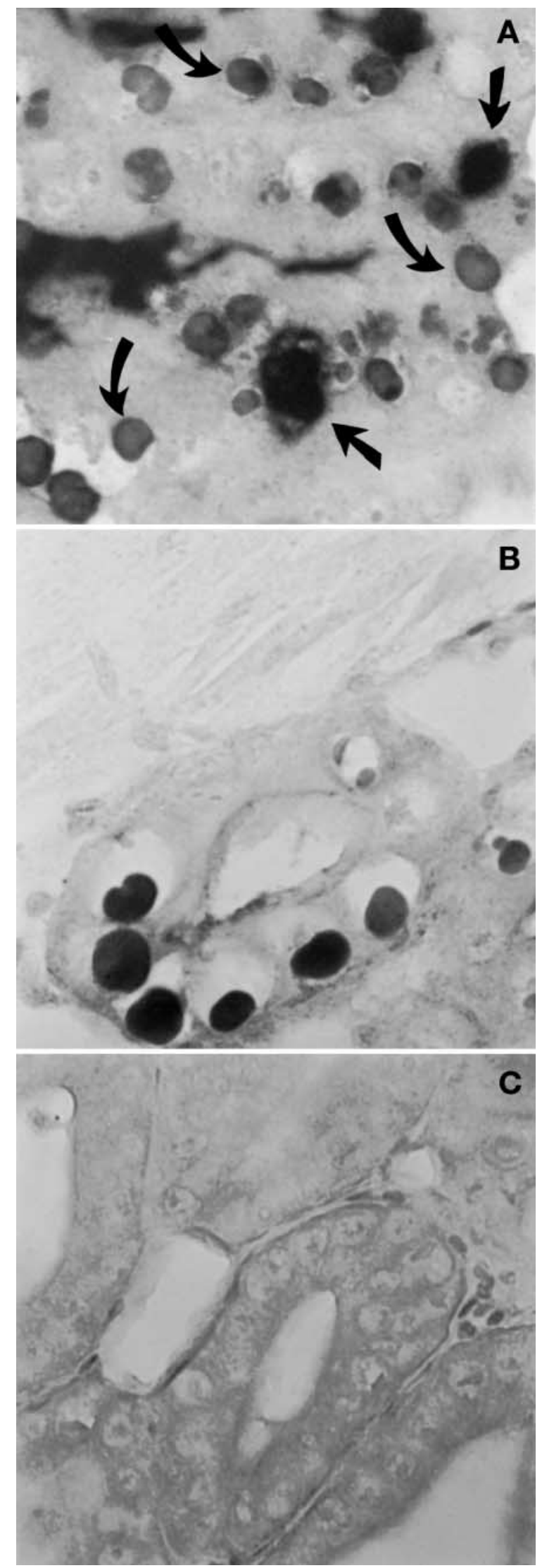

Fig. 3. In situ hybridization results with HPV from Penaeus monodon. (A) HPV-infected hepatopancreatic tissue reaction with the commercial digoxygenin-labeled probe from DiagXotics used at $10 \mathrm{ng} \mathrm{ml}^{-1}$ of probe solution and showing a variable reaction with some HPV-infected nuclei giving a strong reaction (straight arrows) and others little or no reaction (curved arrows). (B) HPV-infected hepatopancreatic tissue reaction with the digoxygenin-labeled PCR fragment derived from HPVmon at $1 \mathrm{ng} \mathrm{ml}^{-1}$ of probe solution showing a more uniform strong reaction. (C) Normal shrimp hepatopancreatic tissue showing no reaction with the digoxygenin-labeled PCR fragment derived from HPVmon at $1 \mathrm{ng} \mathrm{ml}^{-1}$ of probe solution

(Mari et al. 1995). Better in situ hybridization results were obtained using a digoxygenin-labeled probe prepared from the $732 \mathrm{bp}$ HPVmon cloned fragment (Fig. 3B). No signals were seen in normal uninfected tissues or in tissues infected with white spot syndrome virus and infectious hypodermal and hematopoietic necrosis virus for either probe (Fig. 3C). These results also confirmed that the PCR fragment was derived from HPV and not shrimp DNA or DNA of other major shrimp viruses known in Thailand.

Southern blot hybridization: Probable differences between HPVmon and HPVchin were confirmed by Southern blot hybridization results using DIG-labeled HPV DNA OF44, also commercially available from DiagXotics and developed from HPVchin (Mari et al. 1995) (Fig. 4). After PCR products from agarose gel electrophoresis were transferred onto a positively charged nylon membrane and probed with OF44, a strong hybridization signal was obtained with the HPVchin PCR product but only a weak signal with the HPVmon PCR product (Fig. 4). This result supported the PCR results in indicating fundamental differences between HPVchin and HPVmon. It also corresponded to earlier publications reporting different genome sizes for the 2 viruses (Bonami et al. 1995, Sukhumsirichart
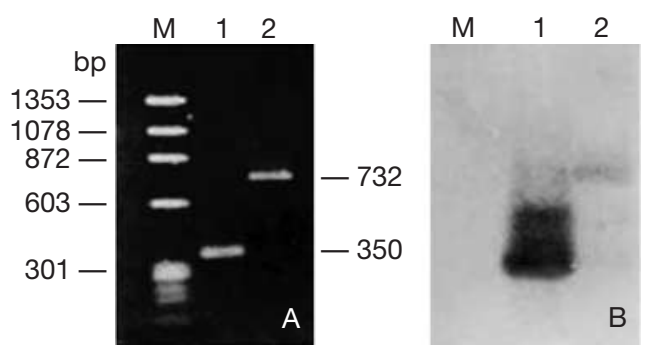

Fig. 4. Agarose gel and Southern blot hybridization of PCR products from HPVchin (350 bp) and HPVmon (732 bp). DNA from the agarose gel in (a) was transferred to a nylon membrane (b) and hybridized with DIG-labeled OF44 (DiagXotics probe). The HPVchin product hybridized strongly with the probe, while the HPVmon product did not. Lane M: $\varnothing \times 174$ / HaeIII DNA size marker. Lane 1: $350 \mathrm{bp}$ PCR amplicon from the HPVchin control template at $100 \mathrm{pg}$. Lane 2: $732 \mathrm{bp}$ PCR product from Thai HPV of Penaeus monodon template at $100 \mathrm{pg}$ 
et al. 1999, respectively). Because of this, the $732 \mathrm{bp}$ HPVmon fragment was cloned for sequence analysis and comparison with known sequences for HPVchin listed at GenBank.

Sequence analysis and alignment. The exact size of the cloned PCR fragment from HPVmon was $732 \mathrm{bp}$ including the $18 \mathrm{bp}$ primer sequences at each end (total $36 \mathrm{bp}$ ). Thus, excluding the primer sequences, the portion corresponding to HPVmon DNA was only $696 \mathrm{bp}$ and it consisted of $47 \%$ GC content. Nucleotide sequence comparison (Fig. 5) showed approximately
$78 \%$ homology with 701 bases within a larger 3350 base fragment of HPVchin DNA listed in the GenBank database (positions 1272 to 1972 in the GenBank fragment). Positions 1642 to 1990 in the HPVchin GenBank fragment correspond to the 350 bases targeted by the DiagXotics PCR primers. In the HPVmon sequence corresponding to these 350 bases (positions 383 to 732 in Fig. 5), the 18 base interval corresponding to the DiagXotics forward primer \#7940 showed significant sequence difference from HPVchin and explained why a 350 bp amplicon was not readily obtained when

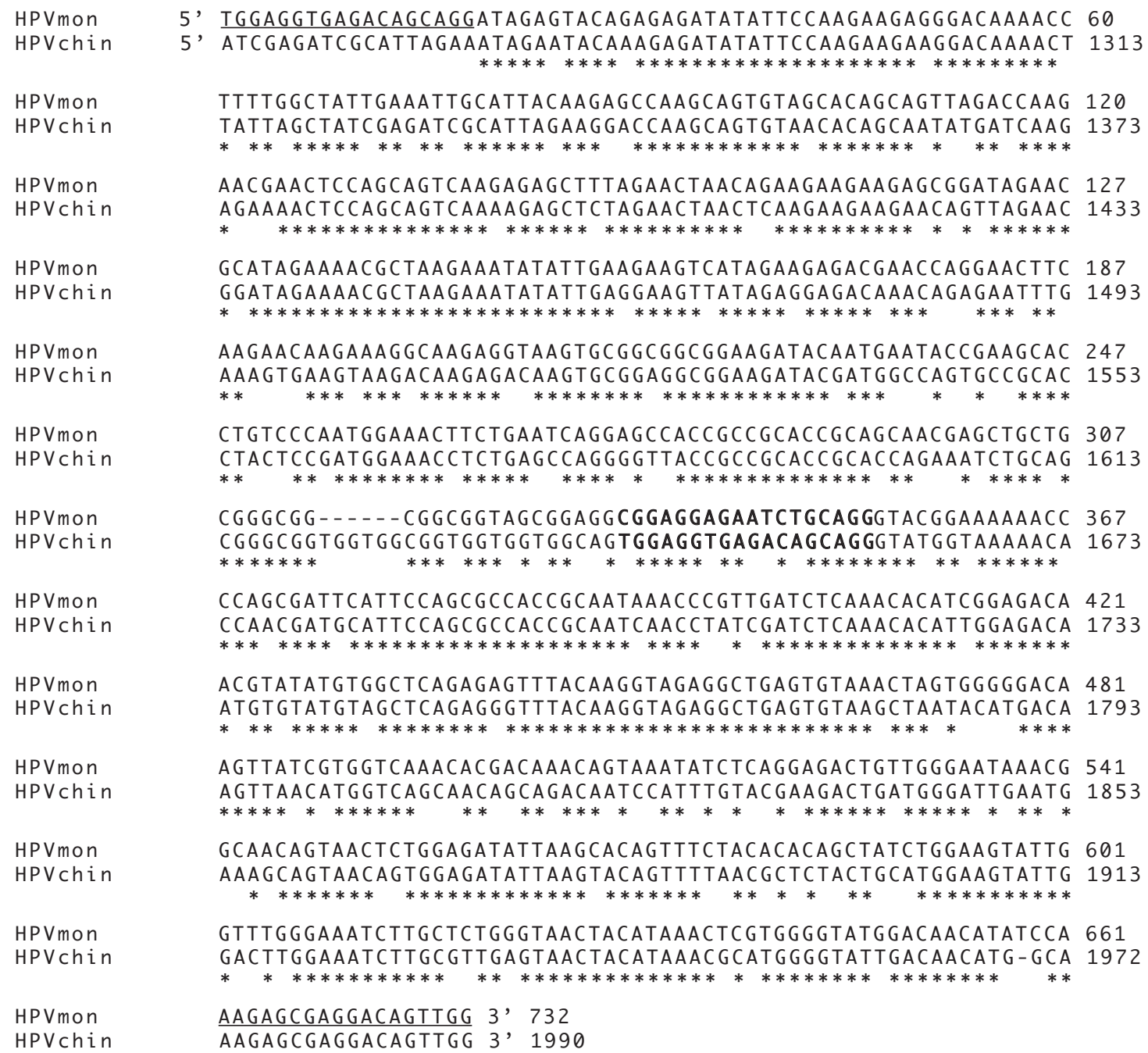

Fig. 5. Sequence alignment between the 732 bp HPVmon DNA amplicon and a portion of a 3350 bp HPVchin fragment from GenBank as determined by Clustal W at the European Bioinformatics Institute website. Base matches are marked with asterisks. Although excluded from the comparison, the 18-mer DiagXotics forward (7490) and reverse (7852) HPVchin primer sequences are underlined, as determined by our sequencing of the $732 \mathrm{bp}$ HPVmon amplicon. The reverse primer sequence obtained for the 3' end of the HPVmon fragment exactly matched the sequence at its target position in the HPVchin genome. However, the position of the forward primer in the HPVchin sequence (bold lettering) had only $71 \%$ homology with the corresponding portion of the HPVmon sequence (also in bold). By contrast, there was only $11 \%$ homology between this forward primer sequence and the matching region at the $5^{\prime}$ end of the HPVmon sequence. The 18-mer primer sequences at the $5^{\prime}$ and $3^{\prime}$ ends of the $732 \mathrm{bp}$ HPVmon PCR fragment were necessarily identical to the sequences of the primers used and the actual target sequences were not determined 
HPVmon DNA is used as a template. The 696 base sequence from HPVmon and the 701 base sequence from HPVchin gave no significant homology to any known DNA sequence in the GenBank database. Putative amino acid sequences were not compared.

Since an additional but faint product of approximately 350 bp was obtained when using high HPVmon template concentrations with the DiagXotics primers, it was possible that the amplicon resulted from weak hybridization of forward primer \#7490 with HPVmon template at the 383 to 400 base positions where the homology was only $72 \%$. If this were so, the amplicon would be internal to the $732 \mathrm{bp}$ amplicon and would readily hybridize to it. To test this hypothesis, the cloned 732 bp PCR fragment from HPVmon was digoxygenin-labeled and used as a hybridization probe in Southern blots of the PCR product from HPVmon. The probe hybridized strongly with both the $350 \mathrm{bp}$ and $732 \mathrm{bp}$ fragments (results not shown). On the basis of this result, we concluded that primer \#7490 could, at high template concentrations, bind sufficiently at positions 383 to 400 in the HPVmon sequence to yield a low quantity of a $350 \mathrm{bp}$ amplification product. However, sequencing of the $350 \mathrm{bp}$ fragment would be required to absolutely confirm this.

The target sequences to which the DiagXotics primers bound in yielding a 732 bp from HPVmon DNA were not determined. However, based on their lower sensitivity with HPVmon DNA template than with HPVchin template, it was likely that the match was not perfect. Taken together with approximately $78 \%$ DNA base homology between the 696 HPVmon and 701 base HPVchin sequences, it is likely that HPVchin and HPVmon are distinct varieties or species of HPV, in spite of the fact that they have the same morphology, tissue tropism and histopathology. This corresponds with publications showing that their genomes differ by approximately $2 \mathrm{~kb}$ in length (Bonami et al. 1995, Sukhumsirichart et al. 1999).

Fortuitously, the DiagXotics primers gave a differential reaction for HPVmon and HPVchin and thus can probably be used for strain identification. However, the sensitivity for the 2 targets is not the same. To overcome this problem, it should be possible to design specific primers that would give non-variable results. Based on short intervals of low homology in the compared sequences of HPVchin and HPVmon presented here, it should be possible to design non-cross-reacting PCR primer pairs that would be capable of detecting either virus specifically. By the same reasoning, intervals of complete homology could be used to design cross-reacting primers that would detect both viruses non-specifically and with equal sensitivity. Alternatively, mixed or degenerate primers could be designed for more general detection of HPV varieties or species.
Acknowledgements. The authors would like to thank the National Center for Genetic Engineering and Biotechnology (BIOTEC), Thailand, for partial support to carry out this work. Thanks also to Dr Vithaya Thamavit and Surapol Kongkim of the Department of Pathobiology, Faculty of Science, Mahidol University for preparation of tissue sections.

\section{LITERATURE CITED}

Bell TA, Lightner DV (1988) A handbook of normal shrimp histology. World Aquaculture Society, Baton Rouge

Bonami JR, Mari J, Poulos BT, Lightner DV (1995) Characterization of hepatopancreatic parvo-like virus, a second unusual parvovirus pathogenic for panaeid shrimps. J Gen Virol 76:813-817

Durand S, Lightner DV, Bonami JR (1998) Differentiation of BP-type baculovirus strains using in situ hybridization. Dis Aquat Org 32:237-239

Flegel TW (1997) Special topic review: major viral diseases of the black tiger prawn (Penaeus monodon) in Thailand. World J Microbiol Biotechnol 13:433-442

Flegel TW, Fegan DF, Vuthikornudomkit S, Sriurairatana S, Boonyaratpalin S, Chantanachookhin C, Vickers JE, Macdonald OD (1992) Occurrence, diagnosis and treatment of shrimp disease in Thailand. In: Fulks W, Main KL (eds) Disease of cultured penaeid shrimp in Asia and the United States. Oceanic Institute, Honolulu, p 57-112

Flegel TW, Thamavit V, Passarawipas T, Alday-Sanz V (1999) Statistical correlation between severity of hepatopancreatic parvovirus (HPV) infection and stunting of farmed black tiger shrimp (Penaeus monodon). Aquaculture 174: 97-206

Lightner DV (1996) A handbook of pathology and diagnostic procedures for disease of culture panaied shrimp. World Aquaculture Society, Baton Rouge

Lightner DV, Redman RM (1985) A parvo-like virus disease of penaeid shrimp. J Invertebr Pathol 45:47-53

Lightner DV, Redman RM, Moore DW, Park MA (1993) Development and application of a simple and rapid diagnostic method to studies on hepatopancreatic parvovirus of penaeid shrimp. Aquaculture 116:15-23

Lightner DV, Redman RM, Poulos BT, Mari JL, Bonami JR, Shariff M (1994) Distinction of HPV-type virus in Penaeus chinensis and Macrobrachium rosenbergii using a DNA probe. Asian Fish Sci 7:267-272

Lo CF, Hsu HC, Tsai MF, Ho CH, Peng SE, Kou GH, Lightner DV (1999) Specific genomic DNA fragment analysis of different geographical clinical samples of shrimp white spot syndrome virus. Dis Aquat Org 35:175-185

Mari J, Lightner DV, Poulos BT, Bonami JR (1995) Partial cloning of the genome of an unusual shrimp parvovirus (HPV): use of gene probes in disease diagnosis. Dis Aquat Org 22:129-134

Pantoja C, Lightner DV (2000) A non-destructive method based on the polymerase chain reaction for detection of hepatopancreatic parvovirus (HPV) of penaeid shrimp. Dis Aquat Org 39:177-182

Sambrook J, Fritsch EF, Maniatis T (1989) Molecular cloning: a laboratory manual, 2nd edn. Cold Spring Harbor Laboratory, Cold Spring Harbor

Sukhumsirichart W, Wongteerasupaya C, Boonsaeng V, Panyim SP, Sriurairatana S, Withyachumnarnkul B, Flegel TW (1999) Characterization and PCR detection of hepatopancreatic parvovirus (HPV) from Penaeus monodon in Thailand. Dis Aquat Org 38:1-10

Submitted: December 11, 2000; Accepted: May 21, 2001

Proofs received from author(s): September 4, 2001 